\title{
A assistência caritativa a infância abandonada e desvalida na cidade de São Paulo no século XIX
}

\author{
The caritative assistance the infancy abandoned and displayed in the \\ city of São Paulo in century XIX
}

\author{
Robson Silva*
}

\section{RESUMO}

Nesse artigo acadêmico será analisada a situação social das crianças abandonadas na cidade de São Paulo durante o século XIX, principalmente a atuação das instituições eclesiásticas no amparo dos pequenos desafortunados, especialmente após a inauguração da Roda dos Expostos em 1825 na Santa Casa da capital paulista. Até o final do século XVIII, o índice de crianças expostas era baixo se comparado com centros urbanos porque as crianças desafortunadas eram acolhidas pelas famílias paulistas, ou pela iniciativa da Igreja Católica motivados pela caridade cristã. Todavia, no século seguinte, a cidade de São Paulo começou a ter um relativo crescimento urbano $\mathrm{e}$ populacional, o que acarretou em diversos problemas sociais. Com isso, houve um aumento significativo dos abandonos de crianças que a caridade não conseguiu absorver. A instalação da roda dos expostos veio para diminuir os índices de abandono e infanticídio. Mas apenas a "Roda" não resolveria a questão, toda uma estrutura assistencial foi montada pela Igreja, com a participação da sociedade, para o atendimento dos expostos: amamentação pelas amas-deleite, adoção pelas famílias, internamento, educação, inserção ao trabalho e casamento para as moças. Esse sistema assistencial fundamentado na caridade religiosa vigorou durante todo o século XIX.

PALAVRA-CHAVE: Historia Social. Demografia. Infância. Instituições. Caridade.

\section{ABSTRACT}

In this academic article the social situation of the children abandoned in the city of São Paulo during century XIX will be analyzed, mainly the performance of the ecclesiastical institutions in the support of small the unfortunate ones, especially after the inauguration of the Wheel of the Displayed ones in 1825 in the Saint-House of the São Paulo capital. Until the end of century XVIII, the index of displayed children was low if comparative with urban centers because the unfortunate children were received by the São Paulo families, or for the initiative of the Church Catholic motivated by the Christian charity. However, in the following century, the city of São Paulo started to have a relative urban and population growth, what it caused diverse social problems. With this, it had a significant increase of the abandonments of children who the charity did not obtain to absorb. The installation of the wheel of displayed the lode to diminish the indices of abandonment and infanticide. But only the "Wheel" would not decide the question, all a assistencial structure was mounted by the Church, with the participation of the society, for the attendance of the displayed ones: breast-feeding for love-of-milk, adoption for the families, internment, education, insertion to the work and marriage for the young women. This assistencial system based on the religious charity invigorated all during century XIX.

KEYWORDS: Social History. Demography. Infancy. Institutions. Charity.

\footnotetext{
* Graduado em História pela Universidade Estadual de Londrina - PR (2008). Atualmente é mestrando do Programa de Pós-Graduação em História Social (PPGHS) pela Universidade Estadual de Londrina - PR com a dissertação: A instrumentalização da infância: estudo sobre as condições sociais e as políticas públicas das crianças marginalizadas na cidade de São Paulo (1888 - 1927) sob orientação do Prof. Dr. J osé Miguel Arias Netto.
} 


\title{
As Crianças Enjeitadas no Universo das Famílias Patriarcais Paulistas
}

A sociedade paulistana do final do sec. XVIII e inicio do sec. XIX ainda mantinha seus laços patriarcais e de parentesco, os costumes provicianos imperavam no cotidiano da pequena vila. Assim, as crianças enjeitadas estavam inseridas dentro da malha de relações sociais das familias patriarcais, incorporando-se como afilhados ou agregados. "É evidente que essa sociedade patriarcal [...] possibilitava a absorção dos inúmeros bastardos e expostos originados da exploração sexual da mulher índia e negra pelo senhor branco, ou pela instabilidade da vida familiar." (MESGRAVIS, 1976, p. 170).

Segundo Laima Mesgravia (1976, p. 171):

\begin{abstract}
Durante o bandeirismo, época, em que não revela a documentação a menor informação a respeito de expostos mas muitas de bastardos, o problema era com certeza solucionado dentro da família patriarcal, com assimilação desses elementos para integrarem o contingente das bandeiras, absorvedoras de homens, ou para trabalharem nas pequenas lavouras de subsistência dos grandes bandeirantes. [...]. Nessa sociedade militarizada o exposto encontrava lugar semelhante ao que ocuparia no feudo medieval, como participante na empresa sertanista. [...]. É nessas pequenas ou médias propriedades, exploradas com trabalho da "família do proprietário e seus agregados que encontramos pela primeira vez menção constante dos expostos.
\end{abstract}

Até meados do séc. XIX, a questão do abandono infantil estava incorporada nos domínios das famílias e entidades religiosas, baseadas no comportamento caridoso e na piedade cristã. Maria Luiza Marcilio (1998, p. 134) assim define o sistema social da caridade:

Do período colonial até meados do século XIX vigorou a fase [...] caritativa. $\mathrm{O}$ assistencialismo dessa fase tem como marca principal o sentimento da fraternidade humana, de conteúdo paternalista, sem pretensão a mudanças sociais. De inspiração religiosa, [...] privilegiam a caridade e a beneficência. Sua atuação se caracteriza pelo imediatismo, com os mais ricos e poderosos procurando minorar o sofrimento dos mais desvalidos, por meio de esmolas ou das boas ações [...], esperam receber a salvação de suas almas, o paraíso futuro e, aqui na terra, o reconhecimento da sociedade e o status de beneméritos. Ideologicamente, procura-se manter a situação e preservar a ordem, propagando-se comportamentos conformistas.

A maioria da população paulista ainda era essencialmente rural e os enjeitados eram absorvidos pelas famílias patriarcais, formando um complexo infantil: a prole senhorial, a prole escrava e as crianças adotadas. Elas submetem-se aos laços de dependência e obediência. "A absorção natural dos expostos no meio rural explica o 
fato de não serem mencionados como problema social nas vilas e na cidade de São Paulo, antes dos primeiros anos do século XIX." (MESGRAVIS, 1976, p. 171) A presença de filhos de criação não estava limitada aos grupos patriarcais, todas as famílias tinham o costume de acolher enjeitados. "O sistema informal ou privado de criação dos expostos em casas de famílias foi o sistema de proteção à infância abandonada mais amplo, e presente em toda a História do Brasil." (MARCILIO, 1998, p. 136) Os benfeitores eram de familias pobres e idosos que não poderiam mais ter filhos. "No entanto, famílias estéreis ou que só puderam ter um ou dois filhos, acabavam "adotando" uma criança abandonada." (MARCILIO, 1998, p. 71) O hábito de acolher expostos deve-se a matriz cultural brasileira, fundada na solidariedade cristã. "Há que considerar que a caridade cristã é uma tradição. Nenhuma criança encontrada na porta de uma casa deveria ser deixada sem cuidados." (MARCILIO, 1998, p. 137) Além do costume do acolhimento, havia também a prática do compadrio, ou seja, adoção dos expostos com afilhado. “Um enjeitado apadrinhado criava imediatamente vínculos de parentesco com uma rede imensa de indivíduos." (VENANCIO, 1999, p. 138) Venâncio descreve a relação de compadrio:

\begin{abstract}
A sociedade brasileira de outrora atribuía grande responsabilidade aos padrinhos. O parentesco espiritual era reconhecido socialmente, implicava respeito e obediência por parte do afilhado, assim como proteção e auxílio por parte de padrinhos e madrinhas. [...] os senhores nunca apadrinhavam os próprios escravos. Acreditava-se que o compadrio e a escravidão eram instituições incompatíveis. [...]. O compadrio criava laços de respeito e proteção superiores às normas escravistas (VENANCIO, 1999, p. 138).
\end{abstract}

No convívio das crianças residentes nas casas-grandes vigorava o princípio do companheirismo nas bricadeiras e jogos. Para Gilberto Freyre (2003, p. 459):

Tanto o excesso de mimo de mulher na criação dos meninos e até dos mulatinhos, como o extremo oposto - a liberdade para os meninos brancos cedo vadiarem com os moleques safados na bagaceira, deflorarem negrinhas, emprenharem escravas, abusarem de animais constituíram vícios de educação, talvez inseparáveis do regime de economia escravocrata, dentro do qual se formou o Brasil.

As funções de trabalho exercidas pelas crianças nas casas-grandes condiziam com a sua constituição física e psíquica, realizavam pequenas tarefas nos serviços domésticos e trabalhos leves, depois eles começariam a labuta na lavoura ou seriam aprendizes. Segundo a descrição de Maria Lucia Barros Mott (1989, p. 89): 
As crianças que ficavam na "casa grande" eram empregadas no serviço particular do senhor e dos familiares deste, Faziam às vezes de pagem, de moleque-de-recados, ou criada; iam buscar o jornal ou o correio nas vilas e cidades da vizinhança; encilhavam os cavalos; arrumavam o quarto; ajudavam a vestir, desvestir e a banhar as pessoas da casa e os visitantes; engraxavam os sapatos; escovavam as roupas; serviam a mesa, espantavam mosquitos; balançavam a rede; abanavam o fogo; buscavam água no poço; limpavam a cozinha; faziam compras; levavam e traziam recados; carregavam pacotes, lenço, leque, vela, missal, guarda-chuva, guarda-sol, etc.

Nas famílias pobres, o recurso de adoção dos expostos foi mais utilizado, pois além da benevolência, estariam garantindo o trabalho delas, mais fiel e menos problemático do que um escravo. "Estas criavam os expostos por espírito de caridade, mas também, [...], utilizá-los, [...], como mão-de-obra familiar suplemenlar, fiel, reconhecida e gratuita; [...], melhor do que a escrava." (MARCILIO, 1997, p. 54).

O trabalho dos expostos enquadrava-se na economia familiar, onde todos executavam tarefas para a sua sobrevivência.

Tal atitude, porém, não é simplesmente explicada pela via da religião. Em uma sociedade escravista [...], os expostos incorporados a uma família poderiam representar um complemento ideal de mãode-obra gratuita. Por isso, criar um exposto poderia trazer vantagens económicas; [...] o "criador" ou a ama-de-leite teriam mão-de-obra suplementar, e gratuita, mais eficiente do que a do escravo, porque livre e ligada a laços de fidelidade, de afeição e de reconhecimento (MARCILIO, 1998, p. 137).

Enfim, a entidade familiar, seja a grande família patriarcal proprietária ou as pobres famílias dependentes de uma economia rudimentar, foi às grandes acolhedoras dos expostos, junto com a Igreja Católica até meados do séc. XIX. Todavia, à medida que São Paulo se desenvolvia urbanisticamente, serão necessários novos mecanismos sociais para atender ao numero crescente de expostos no decorrer do século.

\section{As condições sociais das crianças expostas e a atuação da caridade pela Igreja}

Foi no decorrer do século XIX que a questão da infância abandonada tornouse um grave problema social na cidade de São Paulo. Se até o final do século XVIII, a pacata vila paulista oferecia números insignificantes de expostos, sendo elas tranquilamente absorvidas pela caridade religiosa das famílias e pelas instituições religiosas, isso mudou no século seguinte, devido ao crescimento populacional e urbano. As autoridades politicas sempre negligeciaram o assunto, deixando a solução para as iniciativas de particulares. “Luccock observou no Brasil dos princípios do século XIX 
"grande negligência" [...] com relação ao bem-estar das crianças." (FREYRE, 2003, p. 450) As taxas de abandono eram elevadíssimas. “[...], a taxa de exposição de crianças na cidade de São Paulo, no início do século XIX, era das mais elevadas do Brasil. [...] 15,9\% de todos os nascimentos livres do período." (MARCILIO, 1997, p. 63) Talvez, a hipótese mais forte e visível desse fenômeno seja o elevado nível de prostituição. Na descrição de Saint-Hilaire (1972, p. 187):

E' incontestável que logo após o pôr do sol vêem-se nas ruas muito mais pessoas do que durante o dia; ficam as mesmas repletas de homens e de mulheres que andam à procura de aventuras. Os indivíduos dos dois sexos envolvem-se em capotes de lã, de grandes golas que lhe encobrem a metade do rosto; as mulheres usam um chapéu de feltro preso atrás da cabeça; o dos homens é puxado sobre os olhos. Em nenhuma parte do mundo por mim percorrida vi tamanho número de prostitutas; eram de todas as cores; as calçadas ficavam, [...], cobertas de mulheres dessa baixa espécie. Caminhavam devagar ou esperavam os fregueses nas esquinas; mas, [...], nunca abordavam os homens, nem costumavam injuriá-los ou injuriar-se entre si; olhavam apenas quem passava, conservando uma espécie de pudor exterior, e nada.

Mas como pode ser explicado esse elevadissimo indice de prostituição? Talvez a condição das mulheres esclareça a questão, submetidas num sistema escravocrata, as mulheres, principalmente as mais pobres, sofriam com a falta de trabalho, quando não realizavam pequenos serviços, encontravam na prostituição sua forma de sustento. “ [...], sabia-se que quase $40 \%$ dos moradores da cidade eram mulheres sós, chefes de família, muitas delas concubinas e mães solteiras." (DIAS, 1995, p. 20).

Segundo Mesgravis (1976, p.175):

Já nos referimos à exploração sexual da mulher de cor, índia negra, pelo branco proprietário, propiciada e admitida pela escravidão, e que foi responsável pela multidão de bastardos. Mesmo quando livre, a mulher mestiça ou de cor não escapava dessa degradante exploração, uma vez que os costumes só a aceitavam como concubina temporária, numa união cuja duração dependia tão-somente do capricho do homem. [...], não acreditamos que esses costumes resultassem em uniões definitivas com as mulheres de classe inferior ou de segurança para sua prole.

A maioria das mulheres paulistas sobrevivia sozinhas, abandonadas pelos maridos ou amantes, com filhos para criar. Tiravam seus parcos ganhos do trabalho artesanal, na venda de alimentos e de pequenos serviços, em condições precárias. Maria Odila descreve esse comércio clandestino: 
Brancas pobres, escravas e forras faziam o comércio mais pobre e menos considerado que era o dos géneros alimentícios, hortaliças, toucinho e fumo, nas ruas delimitadas pela Câmara: nas casinhas da rua da Quitanda Velha, na Ladeira do Carmo, chamado "o Buracão", na Rua do Cotovelo [...]. Entre a Igreja da Misericórdia e a do Rosário, as quitandeiras espalhavam pelo chão seus trastes, vendendo um pequeno comércio de vinténs para escravos. O comércio ambulante foi aos poucos tomando becos e travessas entre a Rua do Rosário e a do Comércio: beco do inferno, da Cachaça... a ponto de se queixarem dele os comerciantes da Rua Direita, estabelecidos em suas lojas, reclamando principalmente da sujeira, dos mosquitos e dos maus cheiros. (DIAS, 1995, p. 14).

Então, a prostituição, miséria, a condição precária das mulheres, a falta de trabalho, o abandono dos homens, todos esses fatores reunidos favorecia o aumento do numero de enjeitados. Diante de tal calaminade social, onde os transeuntes encontravam corpos de crianças espalhados pelas ruas ou devorados pelos animais, causava consternação e revolta. "A visão de corpos de recém-nascidos dilacerados chocava a todos. [...]. A descoberta a cada manhã de frágeis corpinhos mutilados, que serviam de pasto a cães e outros bichos, tornou-se sinónimo de barbárie.” (VENANCIO, 1999, p. 24) As autoridades politicas da Provincia tiveram que tomar providencia para solucionar a questão da infancia abandonada. Na citação de Mesgravis da uma idéia da situação dos enjeitados em São Paulo no séc. XIX:

Até 1824 eram as crianças indesejáveis expostas nas portas das casas particulares, nos lugares públicos como igrejas e ruas, ou atiradas em monturos de lixo! O lugar preferido pelas mães ou parteiras eram as casas dos parentes e até dos seus próprios pais, ou de particulares conhecidos pela sua caridade. Muitas vezes, as crianças recolhidas pêlos avós eram batizadas e criadas na qualidade de "afilhados". [...]. O primeiro a revelar interesse por esses infelizes inocentes foi o quarto bispo de São Paulo, D. Mateus de Abreu Pereira, que residindo "na antiga casa de sobrado, de sacadas de rótula, situada à rua do Carmo n. ${ }^{\circ} 20$, sendo que, em frente à mesma casa deste prelado existia um cisqueiro e matos, onde era aí costume enjeitarem crianças... logo que houvia choro de qualquer delas no mesmo lugar, que ficava na esquina da rua e ladeira do Carmo... se apressava em mandar o seu criado buscá-las e, da janela, batisava a mesma criança, receando que os porcos ou outros animais, que por ali andavam, a devorassem antes da chegada do mesmo criado. (MESGRAVIS, 1976, p. 178-179).

O que mais escandalizava as autoridades politicas e a sociedade paulista no séc. XIX não era simplesmente o ato do abandono da criança, mas tambem expo-la ao perigo de vida, caracterizando crime de infanticidio, condenavel tanto pelas regras religiosas, "Abandonar a própria prole consistia em impiedade, em desrespeito aos mandamentos católicos." (VENANCIO, 1999, p. 19) quanto pela justiça criminal. "Considerava-se o infanticídio um crime, ao passo que, no abandono [...] não havia 
qualquer tipo de punição legal.” Todavia, apesar das advertencias legais e religiosas, a pratica do abandono-infanticidio não diminuiu. "O infanticídio era um crime severamente punido. No entanto, era praticado em segredo, [...], camuflado, sob a forma de um acidente: [...]. Não se fazia nada para conservá-las ou para salvá-las." (ARIES, 1981, p. 15). Diante de tal quadro dramático da infância enjeitada, não houve alternativa que não fosse à implantação da Roda dos Expostos em 1825, instalada na Santa Casa de Misericordia pela iniciativa da Igreja. Segundo Marcilio (1998, p. 156):

\begin{abstract}
Depois de muita luta, criou-se a Roda de Expostos. Após a aquisição da Chácara dos Ingleses, no largo da Rua da Glória, em 2 de setembro de 1825, ali se instalaram o Hospital de Caridade e a Roda dos Expostos. Apesar de possuir prédio próprio, suas instalações eram acanhadas e não muito satisfatórias. A Roda ficava em uma janela do andar térreo do casarão. No mesmo ano, duas instituições complementares à assistência da Roda foram criadas: o Seminário da Glória, para meninas, e o de Santana, para meninos. "Eram os seminários, escolas internas destinadas aos filhos de militares pobres e aos expostos da Misericórdia, que, ao deixarem a Santa Casa, depois dos sete anos, ali permaneciam até a maioridade ou até "tomar estado"
\end{abstract}

Além de salvar as pequenas almas do inevitável infanticídio, os religiosos bem tinham a intenção de batizá-las. "Para muitos, o verdadeiro escândalo consistia no fato de os bebés morrerem antes de receber o batismo, [...]." (VENANCIO, 1999, p. 24). Motivados pelo sentimento de caridade, os religiosos incentivavam a entrega dos filhos indesejáveis para as instituições do que deixá-los morrerem pelas ruas. Essa era a diferença entre a piedade humana e o ato criminoso do infanticídio.

Na verdade, os termos "expor" ou "enjeitar" encobriam realidades distintas. Toda mulher que, no meio da noite, deixasse o filho recémnascido em um terreno baldio estava expondo-o à morte, ao passo que os familiares, ao procurarem hospitais, conventos e domicílios dispostos a aceitar o pequerrucho, estavam tentando protegê-lo (VENANCIO, 1999, p. 23).

Depois da sua instalação, a Roda tornou-se o principal depositário das crianças enjeitadas na cidade. "Tais instituições, [...], provêm de mal compreendida filantropia. [...] oferecem elas iniciativa ao afrouxamento dos costumes, mas ainda estimula a mais clamorosa das desumanidades." (KIDDER, 2001, p. 77) As crianças atendidas pela Misericórdia eram encaminhadas ao batismo e seriam registradas, depois receberiam os primeiros cuidados, sendo encaminhadas para as amas-de-leite.

Marcilio (1998, p. 146) descreve esses procedimentos: 
Os expostos que se expõem na Roda, logo que ali chegam encontram amas-de-leite em número suficiente para os alimentar, amas governadas por uma Regente, que mora com elas, [...]. Recebem o feto de cueiros e camisas e mais enxovais, que lhes dá a Casa, em fazenda, paga-se-lhe $4 \$ 000$, por mês, por tempo de 18 meses e a despesa de leite; no fim de cada ano, paga-se-lhe mais $2 \$ 400$, a saber, os varões até a idade de 7 anos e as fêmeas até a idade de 10 anos. Por ser tão módico e insignificante esse salário, se não pode exigir das amas que prestem fianças no ato de receberem os expostos, e mesmo porque têm poucas que por eles fiquem, porém a maior parte já é conhecida na Casa, por criarem outras crianças, e essas mesmas dão informações de outras; além disso, os Administradores fazem as suas visitas pela casa das criadeiras, para indagarem do bom ou mau tratamento, e providenciarem o que for necessário. São ainda as criadeiras obrigadas a apresentar as crianças que criam, no ato do pagamento geral que se faz de quatro em quatro meses e aí são examinadas pelo cirurgião em presença das criadeiras. Quando sucede haver mau tratamento, volta logo a criança para a Casa da Roda.

As amas-de-leite foram às principais personagens desse período da caridade a infância desvalida no Brasil. "Eram as amas-de-leite em sua quase totalidade mulheres extremamente pobres, solteiras, ignorantes e residentes nas cidades." (MARCILIO, 1997, p. 75) Devido a sua ignorância, as amas eram muito descuidadas com a higiene da amamentação, causando a morte das crianças:

A pobreza das amas era acompanhada, naturalmente, da ignorância e da falta de conhecimentos e prática das regras mais elementares de higiene. "A criadeira é uma mulher ignorante dos mais comezinhos preceitos de higiene. Essa ignorância lhe é apanágio próprio... Descuida da alimentação e do trato das crianças... A ânsia do lucro faz com que receba nos seus cómodos maior número de crianças do que eles podem comportar... Falta-lhe o carinho de mãe", denunciavam. (MARCILIO, 1998, p. 249).

O sistema de amamentação pelas amas-de-leite perdurou por todo século XIX, somente sendo criticada pela medicina nas décadas finais daquele século, com o desenvolvimento da pasteurização do leite e outros progressos científicos, como o desenvolvimento da puericultura no século XX.

\section{A Criação das Crianças Expostas e a Sua Educação Através do Trabalho Precoce}

Na época da instalação da Roda dos Expostos (1825) formam inaugurados dois seminários na cidade de São Paulo. Mas nem todas as crianças expostas seriam internadas nos seminários, alguns ficavam com as próprias amas, que afeiçoavam-se por elas. "As próprias amas-de-leite [...] solicitavam, [...], permissão para ficar definitivamente com as crianças que tinham amamentado." (MARCILIO, 1998, p.136) 
Uma grande parcela expostos eram adotados pelas famílias denominadas criadeiras, se constituam de mulheres sozinhas e sobreviviam do trabalho artesanal ou do comércio clandestino, adotavam os expostos tanto pelo sentimento da caridade como pela praticidade do trabalho infantil. "Havia procura de meninos nas casas pobres de mulheres mais velhas [...]. A demanda era constante nas vizinhanças pobres e também na cidade em geral, [...].” (DIAS, 1995, p. 144) Segundo Marcilio (1998, p. 138):

[...], esses chefes de família pobres, sem meios para adquirir escravos, incorporavam um exposto em sua casa, encontrando assim uma fórmula pouco onerosa e bastante eficiente de obter trabalho gratuito complementar para os serviços domésticos e para as lides de suas roças. As crianças expostas criadas em casas de famílias tinham melhores condições de sobrevivência do que as das instituições.

Essas famílias criadeiras dependiam totalmente do trabalho dos seus dependentes para sobreviverem. "[...], contavam com o trabalho de todos, crianças, adultos, dependentes, agregados. Trabalho infantil [...] é um aspecto da pobreza [...] presente [...], desde as primeiras décadas do século passado." (DIAS, 1995, p. 141). Vivendo desse pequeno comércio, os expostos eram alugados, inclusive com grande circulação, pelas mães criadeiras para diveros serviços. "Além das crianças abandonadas, havia o costume de redistribuíção, no sentido de dar para terceiros criarem”. Durante o século XIX, a utilização do trabalho infantil foi institucionalizando-se, através das instâncias jurídicas, os contratos de locação dos expostos foram sendo utilizados para dar uma ocupação aos vadios e ociosos. Segundo Gislaine Azevedo (1995, p. 48-49):

[...], com o caminhar do século XIX e em virtude da questão escrava, a tutela e também o contrato de soldada vão sofrendo deslocamentos de significado, articulando-se à regulamentação de "novas" relações de trabalho. Em função disso, a soldada acabou sendo intensificada. [...]. Segundo a legislação, existiam dois tipos de locação de serviços: a judicial e a não judicial. A não judicial era a que regulamentava todos os tipos de contratos de locação. A judicial era quando o J uiz de Órfãos determinava "que menores indigentes sejão alugados para serviços domésticos.

Para finalizar, é necessário comentar sobre os internos nas instituições de acolhimento, começando pelo Seminário da Gloria, segundo Mesgravis (1976, p. 184):

O Seminário da Glória foi criado por proposta do presidente da província, [...], em 1824, para servir de internato às meninas órfãs, especialmente de militares, com dotação anual de 600\$000. Foi instalado na Chácara da Glória, [...], tendo mudado por diversas vezes para outros locais. Em 1847 foi criada, anexa ao Seminário, uma Escola Normal, só instalada em 1852 e suprimida em 1956. O nível da educação só melhorou em 1870, quando a direção [...] foi confiada à congregação das irmãs de S. J osé. 
O sistema de assistência a infância feminina foi bem mais organizados do que a masculina. As instituições eclesiásticas tiveram uma preocupação especial com as meninas. "Em relação às meninas, [...] a preocupação de preservar a "virtude" (ou a honra) e o recato, [...]. Cuidava-se para que as meninas [...], não fossem expostas aos "perigos do mundo", [...]." (MARCILIO, 1998, p. 281) Muitas famílias procuravam o Seminário para internar suas filhas, pois não tinham condições de criá-las, de terem um dote e talvez um casamento. "Não só visa, [...], a proteção das meninas durante a infância, mas, [...], providencia seu casamento e [...] um dote de duzentos a quatrocentos mil-réis." (KIDDER, 2001, p. 77-78) Segundo Venâncio (1999, p. 145):

O recolhimento proporcionava lugar de refúgio para as enjeitadas que haviam sido sustentadas pela Misericórdia durante três anos e depois colocadas em casas de família, às vezes com resultados insatisfatórios. [...]: reunia sob o mesmo teto mulheres das mais variadas procedências, era subordinada a autoridades leigas e dependia de recursos advindos de esmolas, legados piedosos, aluguel de imóveis e juros.

Quanto a sua educação, baseava-se no ensino primário. “[...] limitava-se ao ensino de rudimentos de leitura, escrita e aritmética, além da aprendizagem das chamadas prendas domésticas e de trabalhos manuais de agulha e linha." (MORAES, 2000, p. 76) Foi introduzido tarefas domésticas para incutir a cultura do trabalho nas meninas. O magistério era uma alternativa de profissionalização. "Apesar de suas deficiências, [...] representou um primeiro ensaio de profissionalização feminina [...]." (MESGRAVIS, 1976, p. 185) Segundo Moraes (2000, p. 79):

Em 1845, não havendo na Província escola que preparasse professores, quer do sexo masculino, quer do feminino, ficara estabelecido que as alunas do Seminário poderiam ser nomeadas professoras, [...]. Nessa época, [...], as áreas do ensino estavam limitadas à língua portuguesa - [...] - e à aritmética [...] o ensino de prendas domésticas e das seguintes matérias: leitura, escrita, gramática portuguesa e princípios da moral cristã e da doutrina do Estado.

Além do magistério, outro destino comum as internas que alcançavam a maioridade era o casamento, recurso muito utilizado no Seminário para "dar estado" as meninas. Segundo Marcilio (1998, p. 296):

O casamento era o melhor e o mais desejado destino que se poderia dar às meninas sob a tutela da Santa Casa. Para multiplicar os casamentos das expostas, manteve-se, até inícios do século $\mathrm{XX}, \mathrm{o}$ sistema de dotes, oferecidos aos moços que se casavam com as expostas reclusas. 
Sobre os meninos expostos, a sua situação era ainda mais difícil, pois a sociedade não dispensava as mesmas preocupações com eles como acontecia com as meninas. Havia a crença de que seriam mais capazes de sobreviverem, não havendo a necessidade do auxílio da caridade. "O destino dos meninos [...], era mais problemático. [...] não eram alvo das mesmas preocupações [...], como no caso das meninas, [...].” (MARCILIO, 1998, p. 178). A utilização do trabalho dos expostos justificava-se por retira-los da ociosidade "A ideologia filantrópico-burguesa, [...], visava [...], incutindo-lhe não apenas o amor e o hábito do trabalho, mas também comportamentos de submissão e de disciplina." (MARCILIO, 1998, p. 294-295). No período de aprendizagem, os internos eram mandados para casas de mestres e artesãos como aprendizes, sem receber salário, apenas moradia e alimentação. Com o aumento da infância desvalida, o Juizado de Orfãos foi imcumbido de conseguir alguma atividade ou ofício para os expostos.

Na explicação de Marcilio (1998, p. 289):

\begin{abstract}
Antes de ser criado o ensino profissionalizante nas instituições de abrigo ao menor abandonado, [...], enviado a aprender um ofício ou profissão em casas de mestres artesãos ou de negociantes. Em troca de casa, comida, vestuário e do treinamento no ofício do seu benfeitor, o pequeno exposto, antes de completar doze anos, tornavase um aprendiz. [...], nada ganhava. Depois dessa idade poderia-ser contratado à soldada [...], com a aprovação do juiz de órfãos ou do mordomo dos expostos.
\end{abstract}

No decorrer do séc. XIX, o trabalho dos meninos foi sendo institucionalizado. Na época da criação da Roda dos Expostos e do Recolhimento Feminino (1825), surgiu o Seminário de Santanna. “Organizado em [...] rígido caráter disciplinar, essa instituição dispunha-se a facilitar ao menino pobre e desvalido a sua educação industrial." (MORAES, 2000, p. 74). A educação dos internos se dava pela sua inserção precoce ao mundo do trabalho. Seu oficio era ensinado nas oficinas da instituição. Moraes descreve esse aprendizado:

O Instituto de Educandos Artífices contava com as seguintes escolas e oficinas: primeiras letras; geometria e mecânica aplicada às artes; noções gerais de aritmética e álgebra; escultura e desenho aplicado às artes; música e instrumentos de corda; ginástica, natação e jogo de armas; alfaiate, sapateiro, marceneiro, serralheiro, correeiro, [...]. Além destas aulas estava previsto, três vezes por semana, o ensino dos exercícios militares (MORAES, 2000, p. 75).

Com a industrialização na segunda metade do século XIX, cada vez mais as crianças eram mandadas para as manufaturas e indústrias como operárias: 
Também passaram a ser solicitados expostos das Rodas para oficinas de artesãos e pequenas fábricas que foram surgindo. Esse sistema funcionava como uma troca de benefícios: para os patrões, que tinham mão-de-obra dócil e gratuita; e para as crianças e jovens, que tinham oportunidade de treinamento e aprendizagem em uma atividade profissional, além da experiência [...] de viver fora do estabelecimento total e enfrentar a realidade tanto familiar como do trabalho (MARCILIO, 1998, p. 290).

O Seminário de Santanna teve que se reinventar aos novos tempos da sociedade industrial, tanto que em 1868 para reformas e implamtação do novo currículo educacional, voltado para a inserção dos internados na nascente indústria paulista.

\section{Ascensão da Filantropia Científica e a Crítica a Caridade da Infância Desvalida}

As discussões, debates e críticas que a sociedade paulista fez nas últimas décadas do sec. XIX às instituições eclesiásticas de amparo as crianças expostas e a ascensão do pensamento filantrópico - cientifico para solucionar com maior eficiência a questão da infância desvalida no Brasil. "A filantropia surgia [...], para substituir o modelo da caridade. [...] atribuiu-se a tarefa de organizar a assistência dentro das novas exigências sociais, políticas económicas e morais, [...]." (MARCILIO, 1997, p. 78) As teorias eugênicas começam a ganhar força na elite intelectual paulista, "É importante lembrar que, durante a segunda metade do século XIX, são difundidas no Brasil as teorias científicas da superioridade da raça branca, que encontram adeptos entre médicos e intelectuais." (VENANCIO, 1999, p. 49) Os médicos higienistas tiveram uma atuação preponderante no século XIX depois do desenvolvimento da Medicina no Brasil. Eles criticavam os problemas crônicos nos hospitais e entidades de caridade.

Marcilio explica a posição medica sobre a caridade:

Os médicos higienistas procuraram atacar a questão da infância abandonada em várias frentes: combate à mortalidade infantil; cuidados com o corpo (estímulo à educação física, aos esportes, à amamentação e à alimentação corretas); estudos; importação de conhecimentos e campanhas de combate às doenças infantis; educação das mães; introdução da Pediatria e da Puericultura, como novas áreas de conhecimento; campanhas de higiene e de saúde pública; etc. (MARCILIO, 1998, p. 194).

Além dos médicos, os juristas também se engajaram na cruzada em favor do reformismo liberal da assistência social a infância desvalida. Até o séc. XVIII esses profissionais limitavam-se nas questões de heranças. No século seguinte suas funções jurídicas foram ampliadas pra atender as demandas sociais, principalmente sobre a 
infância. O J uizado de Órfãos tiveram suas prerrogativas ampliadas para legislar sobre as crianças expostas, entretanto, as leis elaboradas nesse período acabaram colocaram esses impúberes em categorias sociais equivocadas, qualificados de degenerados, ganha força nos textos jurídicos o termo menor, substituindo exposto. "Até mesmo a designação da infância mudou [...]. "Menor" tornou-se o discriminativo da infância desfavorecida, delinquente, carente, abandonada." (MARCILIO, 1998, p. 195). O autor comenta ainda que a justiça descaracterizava as crianças expostas, eram colocadas na categoria de delinqüentes, vadias, ociosas e criminosas. "O termo menor aponta para a despersonalização [...] do jurídico e, portanto, do público. A infância abandonada, que vivia entre a vadiagem e a gatunice, tornou-se, para os juristas, caso de polícia”. Na definição de Marcilio (1998, p. 194):

\begin{abstract}
Por sua vez, no final do século XIX, os juristas deixaram seu campo de atuação tradicional e entraram decididamente no setor da infância desvalida e delinquente. Eles também foram buscar teorias e soluções no exterior. A Itália foi o país de preferência, fiel à tradição milenar do Direito Clássico Romano. [...]. As teorias da Escola de Milão, especialmente as de César Lombroso (das taras hereditárias do criminoso, freadas pela disciplina rigorosa e a ondem, que começam na família), fizeram sucesso aqui, [...]. Uma educação rígida [...] era necessária para refrear a "tendência natural ao crime".
\end{abstract}

As opiniões e críticas dos especialistas não eram um discurso limitado em si mesmo, mas expressavam as aspirações da sociedade, pelo menos para as elites, que respiravam ares de transformações, acreditando no progresso da ciência e na evolução da humanidade. O Estado Republicano, fundamentado no positivismo, apoderando-se das questões sociais. "Havia ainda as ideias positivistas [...] propunham a separação da infância problemática, [...] em grandes instituições totais, [...], antes de devolvê-la ao convívio da sociedade estabelecida." (MARCILIO, 1998, p. 194). Todo assunto social era analisado de maneira sociológica e despersonalizado, fundamentado em teorias européias. Houve a instrumentalização das estruturas de assistência a infância, as crianças expostas do período caritativo se convertem em menores delinqüentes. $\mathrm{O}$ Reformismo propunha a criação das instituições totais, organismo disciplinar fundados na filantropia científica que retiraria as crianças da obscuridade e da ociosidade, transformados em trabalhadores para as indústrias. Conclui Maria L. Marcilio (1998, p. 294):

As Instituições totais criadas em fins do século XIX e inícios do século XX (asilos, reformatórios, colónias agrícolas, colónias penais, correcionais, etc.) mantiveram a filosofia de capacitação profissional dos jovens abandonados e/ ou infratores, mas feita dentro dos estabelecimentos, através de oficinas de artesanato (marcenarias, sapatarias, corte e costura, alfaiataria, funilaria, etc.) que buscavam introduzir os adolescentes em uma atividade profissional. 
Enfim, para finalizar esse capítulo, na passagem dos séculos XIX - XX enormes transformações ocorreram na sociedade brasileira, tendo a cidade de São Paulo como palco. A infância abandonada não ficaria alheia a essas mudanças, saindo da fase da caridade, onde sua situação era tratada nas relações sociais baseadas no paternalismo. Na dinâmica sociedade industrial e burguesa, na fase da filantropia, seu papel social mudou radicalmente, elas serão cooptadas pelo sistema produtivo que não considera suas singularidades, serão enquadradas social e juridicamente em conformidade com sua classe social e se tornaram um joguete dentro capitalismo moderno do século XX.

\section{Referências}

ARIÈS, Philippe. História social da criança e da família. Tradução de Dora Flaskman. 2. ed. Rio de J aneiro: LTC, 1981.

AZEVEDO, Gislane Campos. De Sebastianas e Geovannis: o universo do menor nos processos dos juízes de órfãos da cidade de São Paulo (1871 - 1917). 1995. Dissertação (Mestrado) - Pontifícia Universidade Católica, São Paulo, 1995.

DIAS, Maria Odila Leite da Silva. Quotidiano e poder em São Paulo no século XIX. 2. ed. São Paulo: Brasiliense, 1995.

FREYRE, Gilberto. Casa-grande \& senzala: formação da família brasileira sob o regime da economia patriarcal. Apresentação de Fernando Henrique Cardoso. 48. ed. rev. São Paulo: Global, 2003.

KIDDER, Daniel P. Reminiscências de viagens e permanências nas províncias do Sul do Brasil. Tradução de Moacir N. Vasconcelos. Brasília: Senado Federal, 2001.

MARCÍLIO, Maria Luíza. A roda dos expostos e a criança abandonada na História do Brasil, 1726-1950. In: FREITAS, Marcos Cezar de. História social da infância no Brasil. 3. ed. São Paulo: Cortez, 1997. p. 53-79.

. História social da criança abandonada. São Paulo: Hucitec, 1998.

MESGRAVIS, Laima. A Santa Casa da Misericórdia de São Paulo (1599-1884): contribuição ao estudo da assistência social no Brasil. São Paulo: Conselho Estadual de Cultura, 1976. (Coleção Ciências Humanas).

MORAES, Carmem Sylvia Vidigal. A normatização da pobreza: crianças abandonadas e crianças infratoras. Revista Brasileira de Educação, São Paulo, n. 15, p. 70-96, set/ out/nov/ dez., 2000.

MOTT, Maria Lúcia de Barros. Ser mãe: a escrava em face do aborto e do infanticídio. Revista de História, São Paulo, n. 120, p. 85-96, jan.-jun., 1989.

SAINT-HILAIRE, Auguste de. Viagem à província de S. Paulo e resumos das viagens ao Brasil, província Cisplatina e Missões do Paraguai. Tradução, prefácio e notas de Rubens Borba de Morais. São Paulo: Martins/ Edusp, 1972.

VENÂNCIO, Renato Pinto. Famílias abandonadas: assistência à criança de camadas populares no Rio de J aneiro e em Salvador - séculos XVIII eXIX. Campinas: Papirus, 1999. 